\title{
Influence of Decadal Climate Variability on Growing Degree Day, Precipitation, and Drought in Crop-Growing Seasons
}

\author{
Theepakorn Jithitikulchai \\ World Bank, Bangkok 10330, Thailand; theepakorn@worldbank.org \\ Received: 12 February 2018; Accepted: 9 May 2018; Published: 18 May 2018
}

\begin{abstract}
Knowledge on the impact of climate variability on the decadal timescale is important for policy makers and planners in order for them to make decisions in a range of sectors, including agriculture, water resources, energy, and infrastructure. This study estimates the effects of the ocean-related decadal climate variability (DCV) on growing degree day, precipitation, and drought in the crop-growing seasons of major crops in the United States. The empirical results illustrate that DCV phase combinations are associated with variations in growing degree day, precipitation, and drought across the country using county-level data from 1950 to 2015. There are spatially-differentiated effects on the climate of major production areas of corn, soybeans, and wheat. The annual oscillations in growing degree day, precipitation, and drought reach extreme severity in some DCV scenarios. The results would facilitate the adoption of coping mechanisms with the potential to develop climate risk resiliency for agricultural planning and policy.
\end{abstract}

Keywords: decadal climate variability; growing degree day; precipitation; drought; PDSI

\section{Introduction}

Decadal Climate Variability (DCV) involves persistent ocean-related phenomena existing on at least interdecadal timescales [1-5]. Three forms of DCV are prominent: the Pacific Decadal Oscillation (PDO) [6-10], the Tropical Atlantic Sea Surface Temperature Gradient (TAG) [1], and the Western Pacific Warm Pool Sea Surface Temperature (WPWP) [2,11,12]. Their main findings have been that the major ocean long-run temperature patterns have been associated with multiyear to multidecadal droughts in addition to changes in precipitation patterns.

The PDO is a Pacific Ocean phenomenon that is characterized by two phases: warm and cold. Their phases are identified based on sea surface temperature (SST) anomalies in the North Pacific Ocean $[5,13]$. The PDO phase combinations have persisted for two or three decades in the 20th century [9]. The PDO influences weather through mechanisms of heat transfer between the Pacific Ocean and the overlying atmosphere. Consequently, this phenomenon influences winds in the lower troposphere, and is associated with periods of prolonged dryness and wetness in the western United States and the Missouri River Basin [3]. There is evidence of PDO impacts in the Southern Hemisphere, over the mid-latitude South Pacific Ocean, Australia, and South America [9].

The TAG is a decadal El Niño-like pattern of Atlantic water characteristics that persists for 12 or 13 years. It also has two phase combinations, positive and negative. The TAG is identified through Atlantic sea surface temperature variations in the cross-equatorial dipole pattern [1]. The TAG has been found to be associated with variability in many ocean and atmospheric forces, such as heat transferred between the overlying atmosphere and the Atlantic Ocean, winds in the lower troposphere, and rainfall in the southern, central, and midwestern United States [3]. 
The WPWP is a western Pacific phenomenon and is associated with changes in ocean temperature and in turn with anomalies in surface area, land area temperature, and precipitation, which changes on a 10-15 year period. It is a region of sea surface temperatures warmer than $28.5^{\circ} \mathrm{C}$, extending from the eastern North Pacific to the Gulf of Mexico and the Caribbean on the west of Central America. At its peak, it expands to the tropical waters of tropical North Atlantic on the east [11]. The WPWP exerts influence on the weather over the Great Plains with the positive phase combination and is associated with precipitation and temperature variation in the Great Plains and Western Corn Belt [2].

Each DCV phenomenon has two phase combinations. Jointly, these DCV phenomena have been found to impact drought and extreme weather events over longer time frames $[4,14]$. Researchers have found that DCV-associated variations in major ocean long-run temperature patterns have been associated with multiyear to multidecadal droughts and changes in precipitation patterns [2-5,13-18].

Wang and Ting (2000) [19] found a strong but geographically differentiated association between precipitation variability in the southeastern and northwestern United States and Pacific SST anomalies. Ting and Wang (1997) [6] noted that the year-to-year fluctuations in summertime precipitation over the US Great Plains were significantly correlated with tropical and North Pacific SST variations. Wang et al. (2010) [20] described increases in southeast summer precipitation variability as being primarily associated with SST warming in the Atlantic and also with SST variability across the equatorial Atlantic.

Méndez and Magaña (2010) [21] found that SST anomalies in the North Pacific Ocean led to positive anomalies in the standardized precipitation index over the northeastern United States. They suggest that these anomalies weakened the intensity of the 1950s drought over this region. The Pacific SST was found to alter North American precipitation data [16]. In particular, they found increases in Pacific SST were associated with increased precipitation in northern North America and the Mississippi basin and reduced precipitation over the southwest and eastern United States [16].

Across these studies, the evidence shows the large-scale interdecadal variability of climate forces from North Atlantic Oscillation (NAO), PDO, and WPWP influences the precipitation variability on the Great Plains and the Midwest in addition to effects from El Niño-Southern Oscillation (ENSO) -precipitation variability [22]. Mehta et al. (2012) [18] found that the DCV phenomena have significant impacts in the Missouri River Basin (MRB), altering levels of precipitation and temperature variability plus the incidence of droughts and floods. Their findings indicate that the DCV phenomena explain $60-70 \%$ of the total variance in MRB annual precipitation and water supply. They also found that DCV has a large influence on maximum and minimum temperatures.

To the extent of the author's knowledge from literature review, there are no studies on how the DCV phenomena can alter weather in the crop-growing seasons across the United States. This decadal climate variability study endeavors to advance the literature by reporting the empirical evidence of the impacts of these decadal climate phenomena on local hydroclimatic variables such as growing degree day, precipitation, and drought in the growing seasons of major economic crops, such as corn, soybeans, and wheat. The author conducts an econometric investigation using the annual county-level data from 1950 to 2015. The findings suggested that the DCV phenomena are associated with the changes in growing degree day, precipitation, and drought across the United States. Developing and disseminating the estimates of DCV effects could lead to the collection of valuable information for management and crop enterprise mix alterations, which in turn would increase economic productivity, mitigate climate risk, and empower adaptation to the decadal variability.

\section{Materials and Methods}

\subsection{Data}

This study estimated DCV impacts on growing degree day, precipitation, and drought using the county-level annual data for the period from 1950 to 2015. The final annual data contained 154,013 county-level observations from 2,628 counties in 48 contiguous states. Growing degree day and 
precipitation data were taken from the NOAA Global Historical Climatology Network Daily (GHCND) database [23] to construct the county-level climate data, using historical daily station-level temperature (in degree Celsius, ${ }^{\circ} \mathrm{C}$ ) and precipitation (in millimeters). The threshold temperature for a growing degree day was $10^{\circ} \mathrm{C}$. Any temperature below the threshold temperature was set to the threshold temperature before calculating the average. Likewise, the maximum temperature was determined at 30 Celsius. The inverse-weighting method was used for all stations within $200 \mathrm{~km}$ centroid for each county, where the weights are the inverse of the distance between each station and county's centroid. The annual weather variables were calculated over the eight-month period from March through October, which is the growing season for major crops in the United States, such as March through August for corn and soybeans, and April through October for wheat and cotton.

State-level monthly Palmer Drought Severity Index (PDSI) data for the growing season were drawn from the NOAA National Climatic Data Center's Climate Data Online (NCDC CDO) [24]. Values ranged from -6.0 (extreme drought) to +6.0 (extreme wet conditions) and were averaged across the months in the growing season.

Following Mehta et al. (2011, 2012), the DCV phase combinations construction started with individual indices for each of the three DCV phenomena: PDO, TAG, and WPWP. The PDO index that was derived as the leading principal component of monthly SST anomalies in the North Pacific Ocean poleward of $20^{\circ} \mathrm{N}$ was that developed by Mantua et al. (1997), using monthly data from the Joint Institute for the Study of the Atmosphere and Ocean (JISAO) [25] and had a positive ("warm") and a negative ("cool") phase. The TAG and WPWP indices from NOAA Extended Reconstructed Sea Surface Temperature (ERSST V3b) [26] using the optimal interpolation SST data followed Reynolds et al. (2002) [27], and each also had a positive ("warm") and a negative ("cool") phase. The TAG index was the difference between averaging SST anomalies in a tropical North Atlantic box $\left(5^{\circ}-20^{\circ} \mathrm{N}\right.$, $\left.30^{\circ}-60^{\circ} \mathrm{W}\right)$ and a tropical South Atlantic box $\left(0^{\circ}-20^{\circ} \mathrm{S}, 30^{\circ} \mathrm{W}-10^{\circ} \mathrm{E}\right)$, and the WPWP index was the average SST anomaly in the box bounded by $100^{\circ} \mathrm{E}-160^{\circ} \mathrm{W}$ longitudes and the $25^{\circ} \mathrm{S}-25^{\circ} \mathrm{N}$ latitudinal belt. The annual average of each index over 1950-2015 were computed and subtracted by its annual mean value of seasonal-average SST to get an anomaly index with positive and negative phases. The study filtered the indices with a low-pass Butterworth filter to remove noise and allowed periods equal to or longer than eight years to be passed through. The joint combinations of two phases for each of the three DCV phenomena resulted in eight joint scenarios, and the author classified each year into one of the eight combinations (see Figure A1 in Appendix A). The polychoric correlation matrix of the three DCV phenomena in the years between 1950 and 2015 showed that the binary DCV indices had low correlations with each other, at most 0.16 . Furthermore, the variance inflation factor (VIF) analysis for the regression estimation, using DCV phase combinations that interacted with each of the 48 contiguous states along with other explanatory variables, reported that there was no multicollinearity issue. The sizes of VIF values for any explanatory variables of each DCV phase combination interacted with each contiguous state ranged only between 1 and 1.4 (as a rule of thumb, if VIF $>10$, then multicollinearity is high).

The ENSO phase information from the NOAA Oceanic Niño Index (ONI) was used for identifying the phases of El Niño, Neutral, and La Niña. Following NOAA National Centers for Environmental Prediction (NCEP) [28], El Niño events were designated when the index was at or above +0.5 for five consecutive months in a year. La Niña events were designated when the index was at or below -0.5 for five consecutive months. The rest of the ENSO occurrences were Neutral events (see Figure A2 in Appendix A). The ENSO scenarios took the regional level into account as a control variable for annual phase. 


\subsection{Model Specification}

To estimate DCV effects on observed weather variables, this study used a skew-normal regression approach for an estimation of the mean, variance, and skewness [29-32]. A random variable $Y$ has a skew-normal distribution, denoted by $S N\left(\xi, \omega^{2}, \alpha\right)$, with the following density:

$$
f_{S N}\left(y ; \xi, \omega^{2}, \alpha\right)=2 \omega^{-1} \varphi(z) \Phi(\alpha z)
$$

for $y \in(-\infty, \infty)$ where $z=\omega^{-1}(y-\xi), \xi \in(-\infty, \infty)$ is a location parameter, $\omega>0$ is a scale parameter, $\varphi($.$) and \Phi($.$) are the probability density function and cumulative distribution function of$ the standard normal distribution. This distribution is skewed to the right when $\alpha>0$, skewed to the left when $\alpha<0$, and reduces to a normal distribution when $\alpha=0$.

From centered parameterization for the univariate skew-normal distribution [33], one can obtain $\gamma=(4-\pi) \operatorname{sign}(\alpha)\left(\mu_{z} / \sigma_{z}^{2}\right)^{3} / 2$, which denotes the "skewness index", where $\mu_{z}=\sqrt{2 / \pi} \delta$, $\sigma_{z}^{2}=1-2 \delta^{2} / \pi$, and $\delta=\alpha / \sqrt{1+\alpha^{2}}$. The use of this center-parameterized skewness index $\gamma$, acquired by centering $Y \sim S N\left(\xi, \omega^{2}, \alpha\right)$, is for the ease of inferring the actual magnitude of the departure from normality.

This study then estimated a linear regression assuming the error terms are skew normal:

$$
y=\beta_{0}+\beta_{1} x_{1}+\ldots+\beta_{p} x_{p}+\varepsilon
$$

where $y$ was a dependent variable such as growing degree day, precipitation, or PDSI; $x_{1} \ldots x_{p}$ were independent variables which were dummy variables for DCV combinations that interacted with dummy variables for the US contiguous states and dummy variables for ENSO phase that interacted with dummy variables for agricultural regions, time trends, and county-specific dummy variables; $\beta_{0} \ldots \beta_{p}$ were the regression coefficients to be estimated; and $\varepsilon$ was the skew-normal error term $\varepsilon \sim S N\left(0, \omega^{2}, \alpha\right)$. It followed that the distribution of dependent variable was also skew-normal, which this model setting was consistent with the empirical evidence in growing degree day, precipitation, and PDSI distributions from their statistically significant skewness, as illustrated below.

This study estimated the effects of DCV phenomena on growing degree day, precipitation, and drought at a state-level model setting using annual county-level data. The regional ENSO variables controlled for shorter-period variation by agricultural regions, removing a possible influence of ENSO from DCV. The panel estimation accounted for the temporal and spatial heterogeneity by incorporating time trends and county-specific dummy variables. The statistical inference for estimated coefficients were based on their cluster-robust standard errors, allowing for intragroup correlation at the county-level. Thus, the approach was made robust to heteroskedasticity and spatially correlated errors.

\section{Results}

This section starts with stylized facts for distributional characteristics of growing degree day, precipitation, and drought in the crop-growing seasons in the United States. Then, these weather variables are illustrated for their variations by DCV phase combinations. Finally, the section provides econometric results of DCV impacts on weather variations across the country at the state-level.

Figure 1 reports residual density estimates using histograms and fitted skew-normal distributions for growing degree day, precipitation, and PDSI (from upper to lower panels). Each graph plots the residual density estimate of fitted values from the skew-normal distribution against the nonparametric residual density, which is estimated with histogram plots. The author first fits a skew-normal distribution estimation and examines the distribution of residuals from its fit. The unconditional residual density estimates of the raw county-level data for the period of 1950-2015 provide evidence that their residual densities expressing departure from normality are not symmetrical. Mean estimates are computed from the formula of the skew-normal distribution given in Equation (1). Note that if we estimated a nonparametric kernel distribution or histogram for the raw data, we would obtain exactly 
the same shape, skewness, and height for the distribution as in the unconditional case in Figure 1, except for the location of its mean.
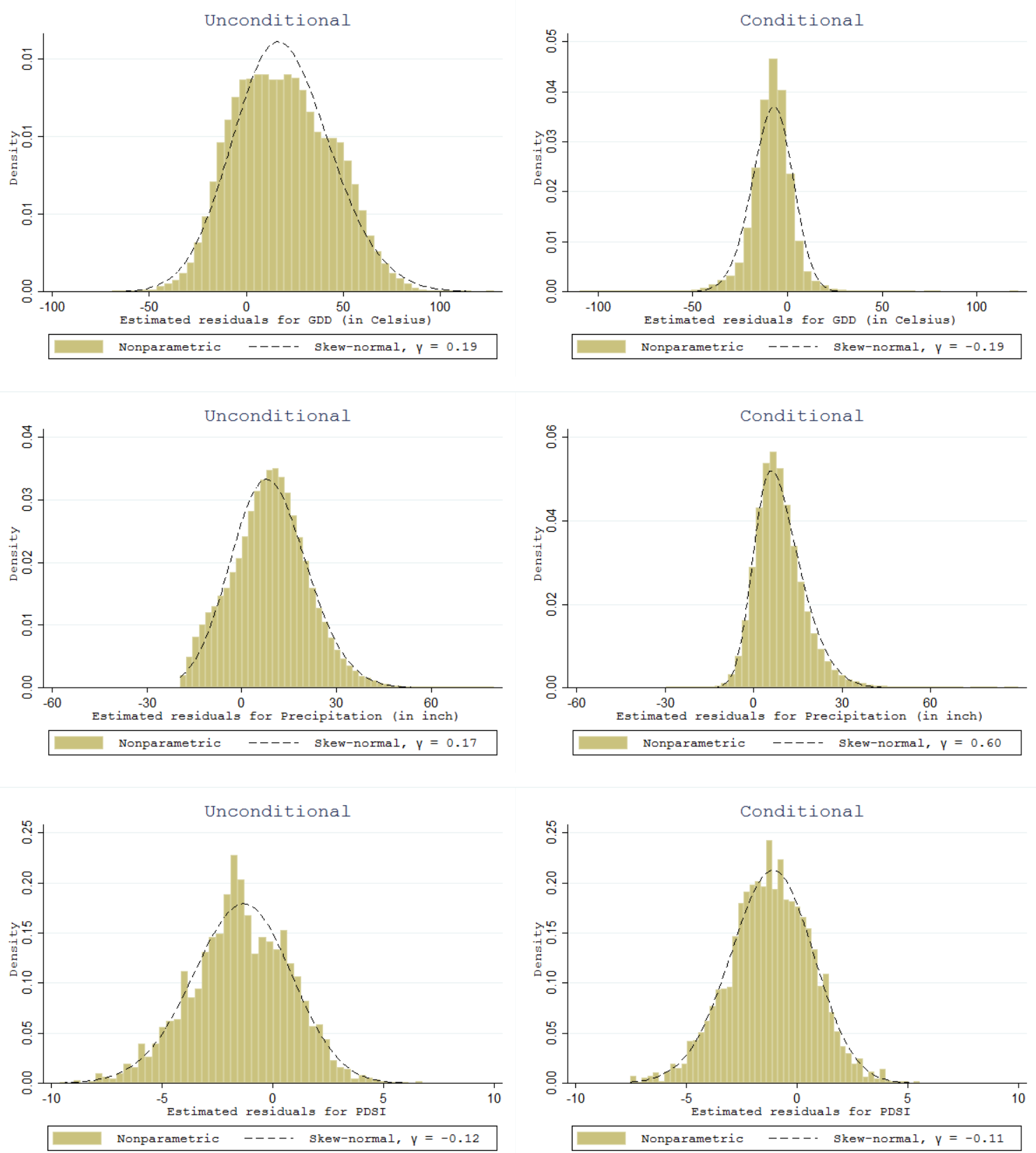

Figure 1. Histogram and skew-normal residual density estimates of growing degree day (GDD), precipitation, and drought (PDSI). The unconditional density estimates use the raw county-level data for the years between 1950 and 2015. The conditional density estimates are from the fitted skew-normal regression with year and county dummy variables.

In statistics, the conditional mean or conditional expectation of a random variable is its expected value given that a certain set of "conditions" is known to occur. In this study, the unconditional residuals are simply obtained from the observed residuals that deviated from the expected mean of growing degree day, precipitation, and PDSI. On the other hand, the conditional expectation of growing degree day, precipitation, and PDSI is the expected value of itself given a conditioning set of time and space variables along with the regional dummy variables of El Niño and La Niña, e.g., in its simplest 
form $E\left(y \mid x_{1} \ldots x_{p}\right)=\beta_{0}+\beta_{1} x_{1}+\ldots+\beta_{p} x_{p}$. Therefore, the conditional residual distribution of the weather variables of interest is the distributional deviations from the conditional expectation controlled for year and county covariates.

From Figure 1, the conditional residual density estimates from a skew-normal regression controlled for temporal and spatial heterogeneity, with less dispersions after controls, reveal the same results as the unconditional residual density estimates that confirm the skew-normal distributions. Therefore, this empirical evidence provides validity in modeling the skew-normal regression for growing degree day, precipitation, and PDSI.

Figure 2 illustrates variations in the mean of growing degree day, precipitation, and PDSI from upper to lower bar graph panels in different DCV phase combinations. The unconditional means are estimated using the raw county-level data for 1950-2015, and the conditional means are obtained from the fitted skew-normal regression with year and county dummy variables. The $95 \%$ confidence intervals used here are $\left(\bar{x}-t_{\alpha} \frac{s}{\sqrt{N_{e f f}}}, \bar{x}+t_{\alpha} \frac{s}{\sqrt{N_{e f f}}}\right)$, where $s$ is the standard deviation and $t_{\alpha}$ is the critical value from the Student's $t$ distribution with $\alpha=0.05$, which both statistics were calculated with the $N_{\text {eff }}$ effective degree of freedom. The $N_{\text {eff }}$ effective degree of freedom followed [34] for $N_{e f f}=N \times\left(1-r^{2}\right) /\left(1+r^{2}\right)$, where $r$ is the values of autocorrelations at a lag of one year for each DCV case, as similar to [35-37]. The conditional means could be slightly different from the unconditional means especially for precipitation possibly due to the skewness in their distribution. Nevertheless, the estimation results of unconditional and conditional mean are consistent across different DCV phase combinations.
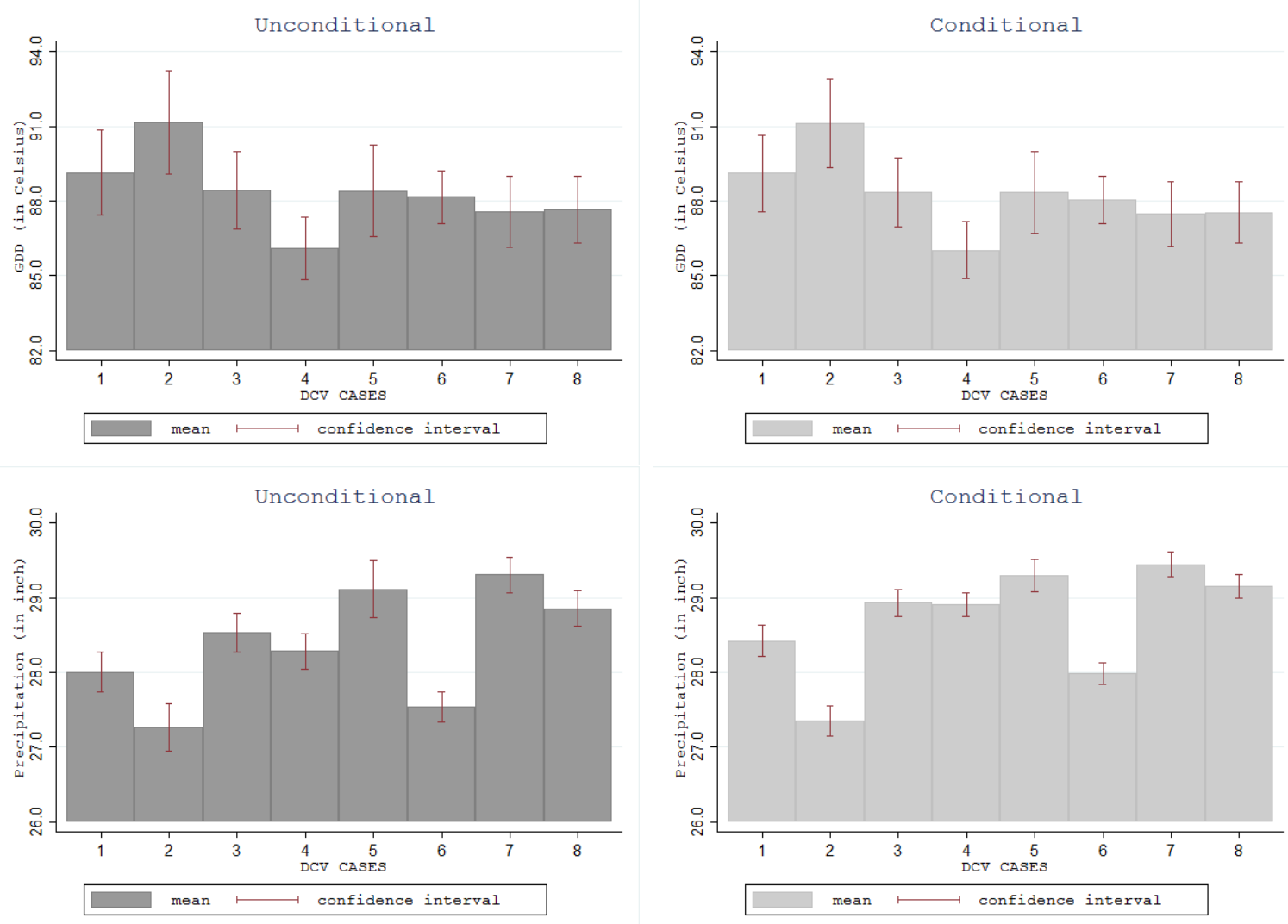

Figure 2. Cont. 

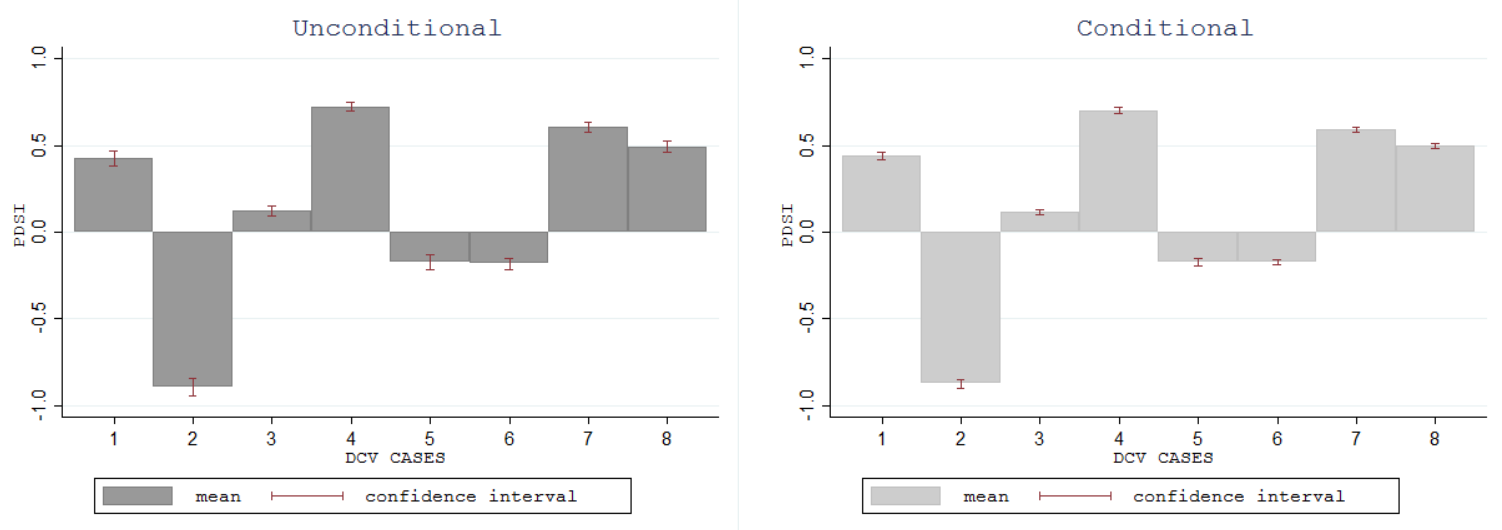

Figure 2. Mean and confidence interval of growing degree day (GDD), precipitation, and drought (PDSI). The unconditional sample means use the raw county-level data for the years between 1950 and 2015. The conditional sample means are from the fitted skew-normal regression with year and county dummy variables. The eight DCV phase combinations are (PDO+, TAG-, WPWP-), (PDO-, TAG+, WPWP-), (PDO- , TAG-, WPWP+), (PDO+, TAG+, WPWP-), (PDO+, TAG-, WPWP+), (PDO-, TAG+, WPWP+), (PDO+, TAG+, WPWP+), and (PDO-, TAG-, WPWP-), respectively.

Therefore, the evidence illustrates that the DCV phenomena alter growing degree day, precipitation, and PDSI at the national averages. For example, under the (PDO-,TAG+,WPWP-) phase, growing degree day is highest, precipitation is lowest, and drought is most prominent. Similarly, other DCV phase combinations have different variations of the three weather variables. The ranges which are the difference between the lowest and highest values for growing degree day, precipitation, and PDSI are $5.06{ }^{\circ} \mathrm{C}, 2.04$ inches, and 1.62 PDSI units, respectively.

Furthermore, the sample means of growing degree day, precipitation, and PDSI by DCV phase show that, at the national averages, they are correlated to others. A DCV phase with high (low) average growing degree day tends to have low (high) precipitation and low (high) PDSI. The pairwise correlation coefficient of national averages between growing degree day and precipitation is -0.55 , between growing degree day and PDSI is -0.83 , and between precipitation and PDSI is 0.58 .

\section{State-Level DCV Effects on Climate}

The DCV phase combinations were found to have an influence on growing degree day, precipitation, and drought across the United States. In general, the DCV phase combinations have spatially varying and statistically significant effects for the 48 contiguous states as shown in Figures 3-5. Their full results of skew-normal regression models are reported in the Supplementary Information. The ordinary least squares regression (OLS) estimation results are also available in the table as the reference comparison of estimates. The estimated regression coefficients and their statistical significance from both OLS and skew-normal models are very similar. 

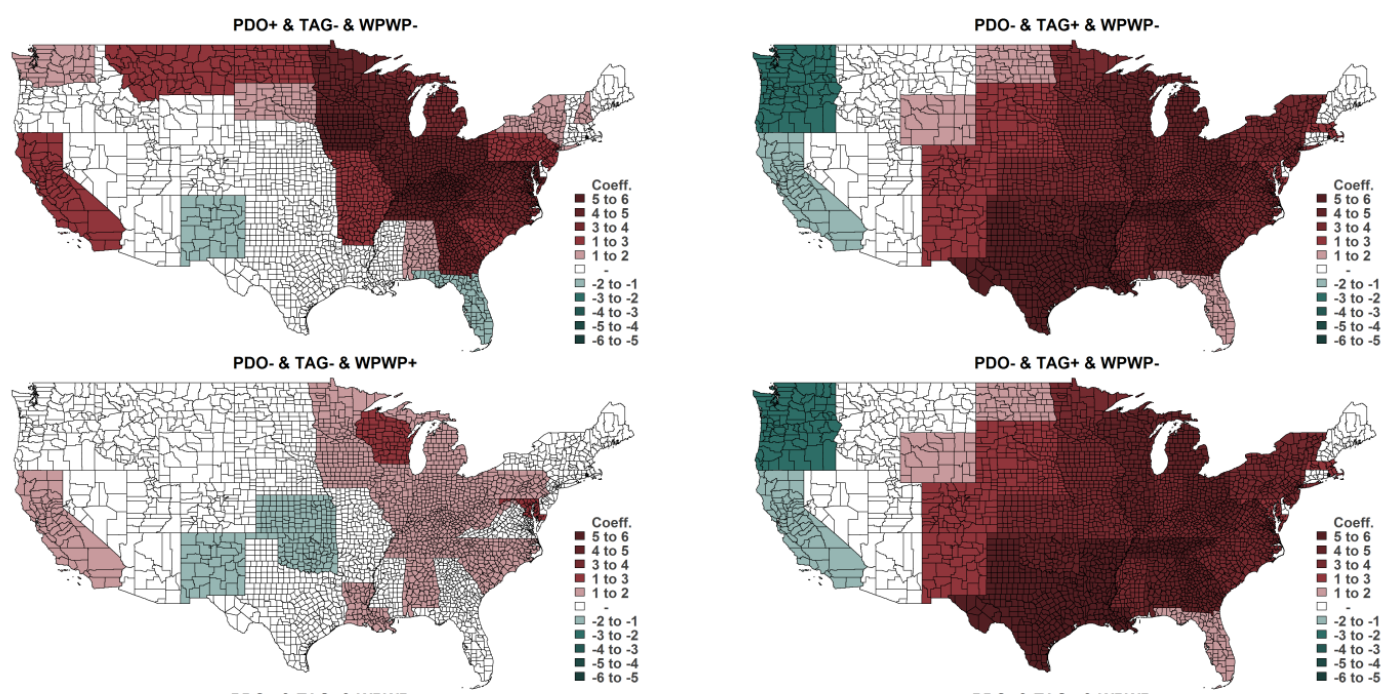

PDO+ \& TAG- \& WPWP-

PDO- \& TAG + \& WPWP+
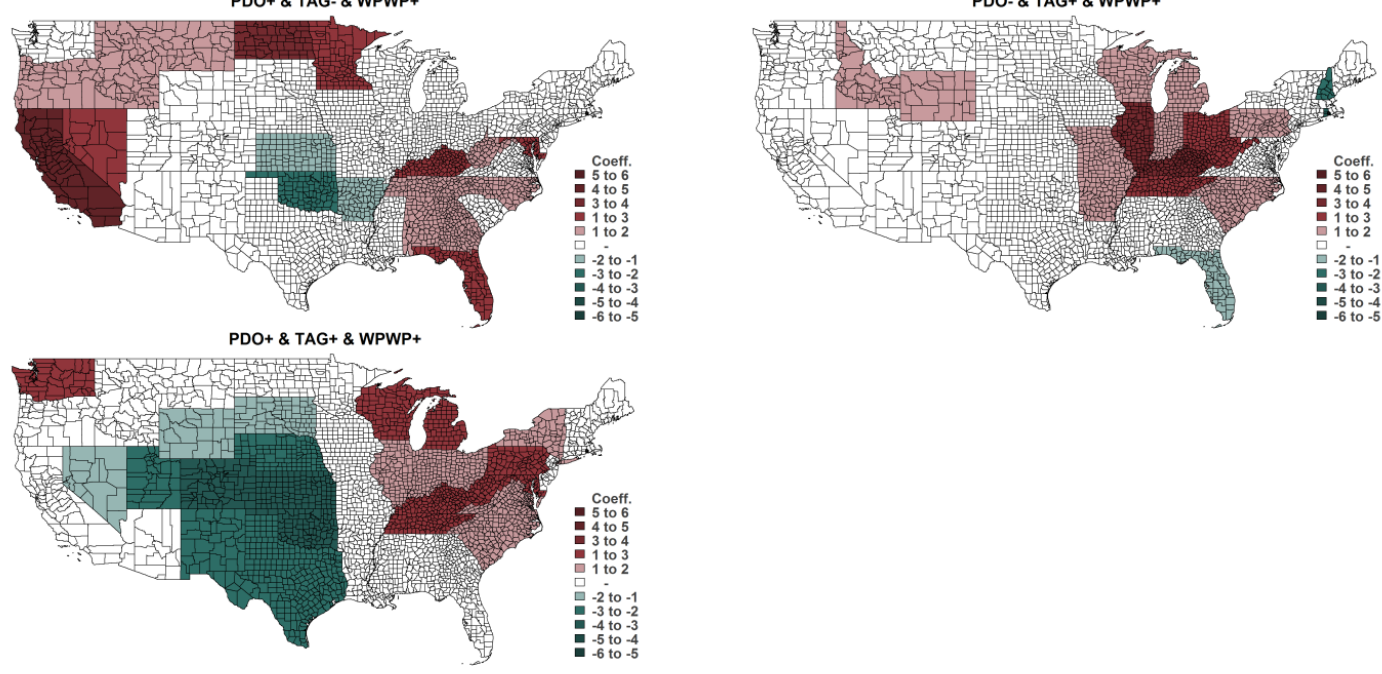

Figure 3. DCV impacts on growing degree day (GDD) by contiguous state (in Celsius).
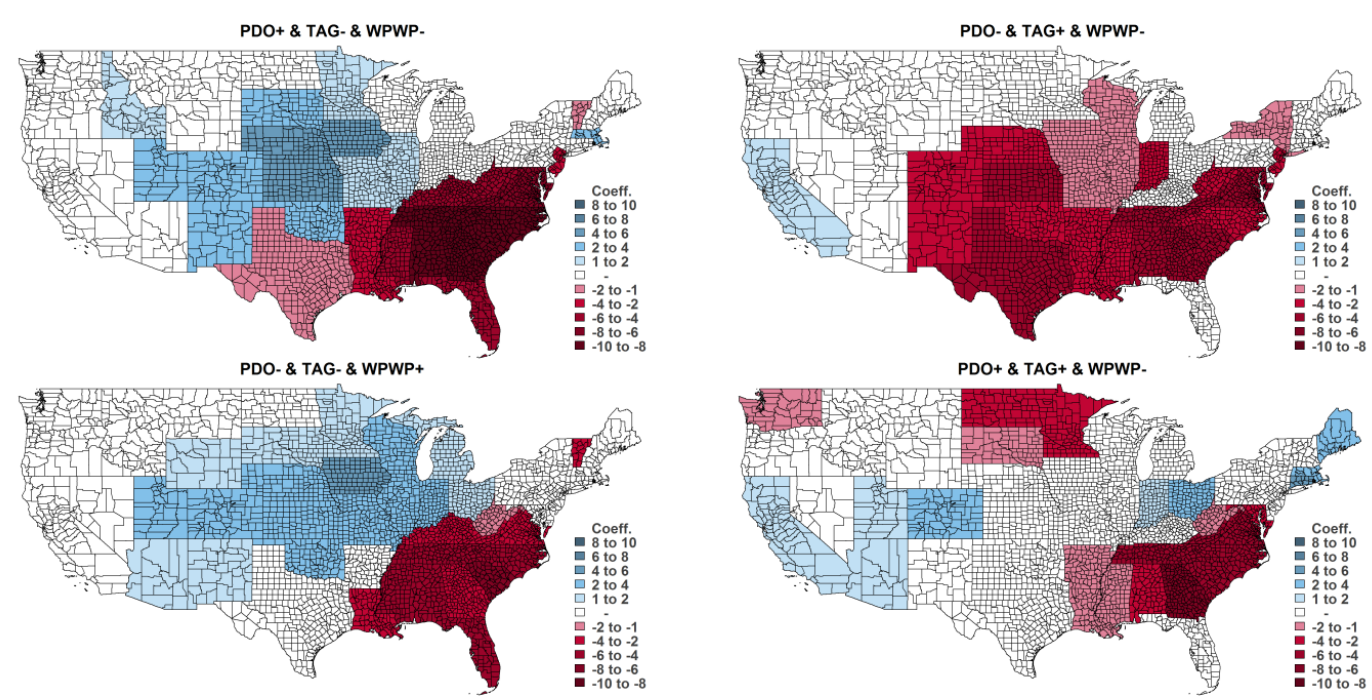

Figure 4. Cont. 

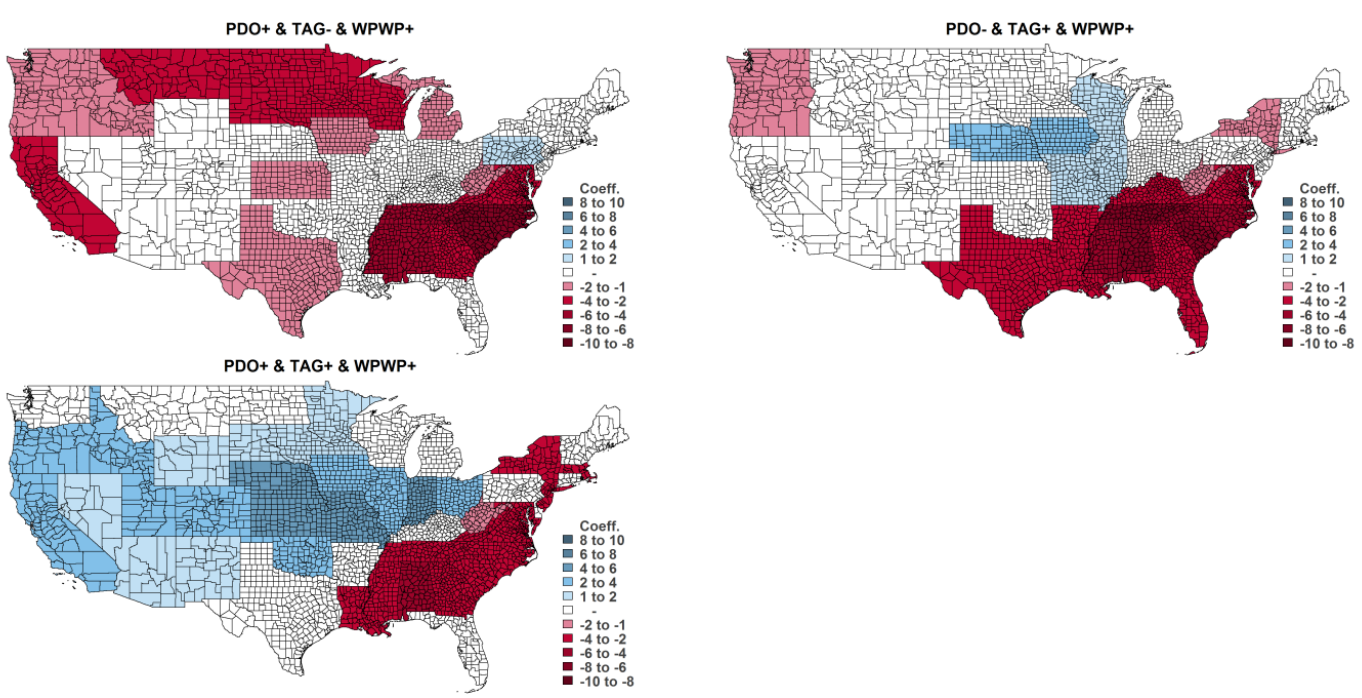

Figure 4. DCV impacts on precipitation by contiguous state (in inch).
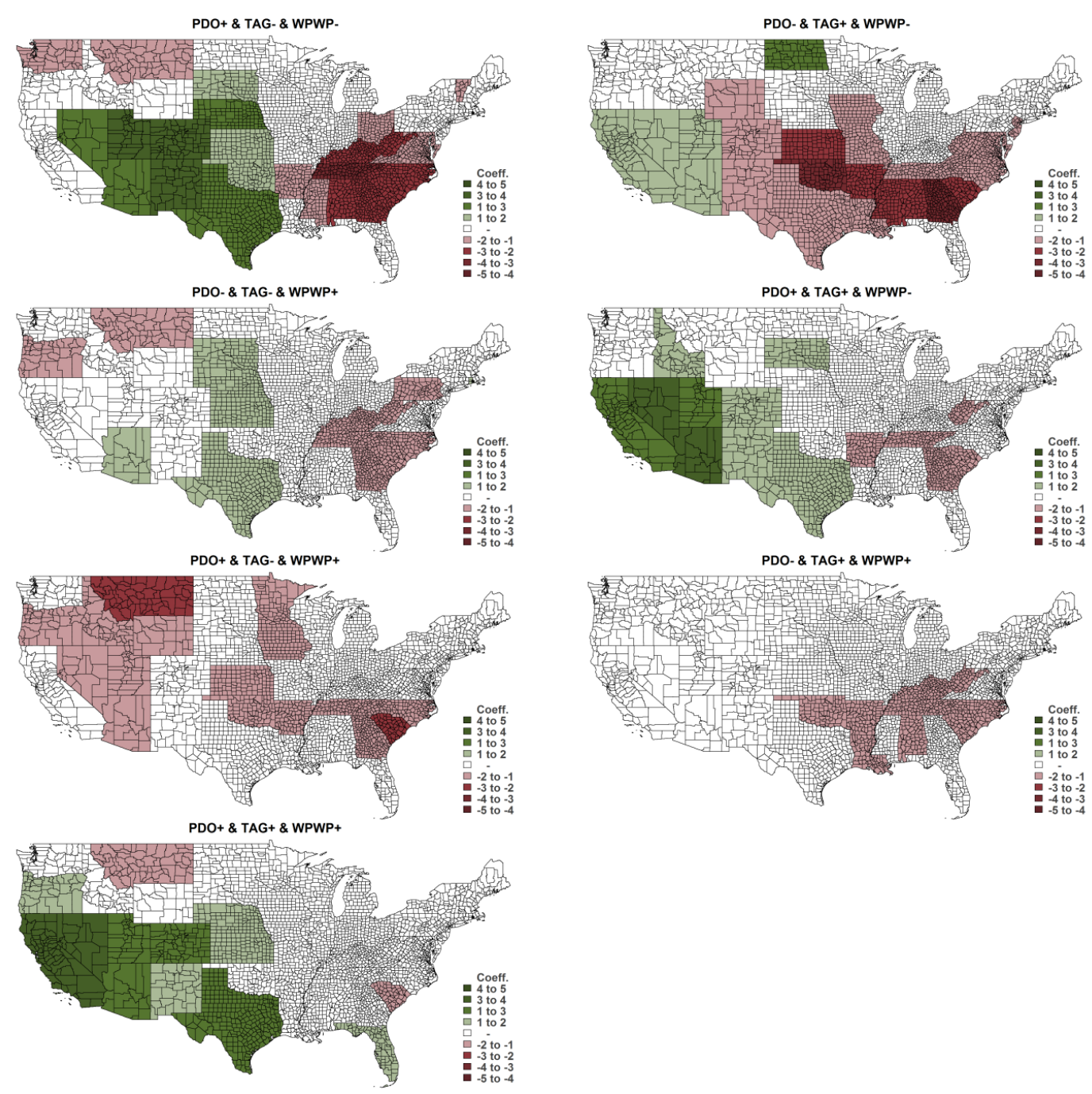

Figure 5. DCV impacts on drought (PDSI) by contiguous state (in index unit). 
The empirical results suggest the skewness in density functions of growing degree day, precipitation, and PDSI; therefore, the skew-normal regression should provide more accurate estimates. The $R$-squared values provide goodness of fit for the OLS regression model as the benchmark indicating how well the linear regression can explain the relationships for the dependent variables such as growing degree day, precipitation, and PDSI with the DCV phase combinations and other explanatory variables. The $R$-squared values for the OLS estimations are $0.9,0.6$, and 0.2 for growing degree day, precipitation, and PDSI, respectively. The $R$-squared values indicated that the observed outcomes of growing degree day and precipitation could be explained well by their estimated regression model. However, low $R$-squared value for PDSI possibly occurred from the fact the PDSI information is state-level, while the county-level data was used. The author made the PDSI regression results available even with low $R$-squared value, because they are consistent with the DCV impacts on growing degree day and, in particular, precipitation. The skew-normal regression has no $R$-squared results, as it is estimated with the maximum likelihood estimation approach.

Figures 3-5 report DCV impacts on growing degree day, precipitation, and PDSI by contiguous state. The figures show the associations with combinations of positive and negative phases of DCV phenomena. Relative to the null-DCV phase combination (PDO-, TAG-, WPWP-), the estimated coefficients presented in these figures are obtained from interactions of dummy variables for DCV phase combinations and dummy variables for contiguous states in the skew-normal regression using annual county-level weather data described earlier. Estimated coefficients illustrated here are only those with $95 \%$ confidence with the cluster-robust $p$-value $<0.05$.

The DCV phase combinations have an influence on growing degree day, precipitation, and drought during the crop-growing seasons in the Corn Belt states and the Southeast states, except Florida, which are the major producers of corn, soybeans, and wheat. The (PDO+, TAG-,WPWP-) phase combination increases growing degree day and precipitation for many contiguous states in the Central and Northern Plains regions such as Iowa, Illinois, Nebraska, Indiana, North Dakota, South Dakota. Furthermore, the (PDO+, TAG-, WPWP-) phase increases growing degree day and drought but decreases precipitation in the Southeast region such as Tennessee, Kentucky, North Carolina, and South Carolina.

However, the (PDO-, TAG+, WPWP-) phase has impacts on increased temperature and decreased precipitation, especially for almost all states in the Missouri River Basin and Southern Plains regions for many major crop-growing states. The (PDO-, TAG+, WPWP-) phase also increases drought extensively in the Southeast and Southern Plains regions except only Florida.

The (PDO+, TAG-, WPWP+) extensively increases growing degree day, decreases rainfall, and increases drought in many contiguous states. The (PDO-, TAG-, WPWP+) phase also increases temperature and decreased rainfall in several states, but the impacts varied by region with lower impacts than the (PDO+, TAG-, WPWP-) and (PDO-, TAG+, WPWP-) phase combinations. All other DCV phase combination impacts are provided in Figures $3-5$.

\section{Discussion}

The oscillations in the growing degree day, precipitation, and drought in many contiguous states of the United States reach extreme severity in some DCV scenarios, such as under the (PDO-, TAG+, WPWP-) or (PDO+, TAG-, WPWP+) phase combinations. In addition, other DCV phase combinations have regionally differentiated effects on growing degree day, precipitation, and drought, with both increases and decreases found. The reasons for how the decadal variability indices jointly influence the weather in the United States are unknown to the author, and the unidentified mechanisms underlying in the DCV impacts provide an unsolved problem for future research in atmosphere and climate physics. Nevertheless, this preliminary assessment provides the estimated impacts of the DCV under each phase combination of three indices of the decadal climate variability.

To check the validity of the results, the author compares the estimated DCV effects with those from Mehta et al. (2012) [18] for the Missouri River Basin region. They found strong DCV phenomena 
associations with regional temperature and precipitation. Specifically they found that during PDO+, precipitation was above average almost everywhere and temperature was lower than average. In the TAG+ phase, they found precipitation was below average almost everywhere and temperature was increased almost everywhere. In terms of WPWP impacts, they found the effects varied geographically and generally had less impact than PDO and TAG. This study has essentially the same results as in Mehta et al. (2012) [18] with almost all of the statistically significant terms having the same sign of effects. Collectively, the results in Central, Mountains, and Northern Plains such as Iowa, Illinois, Nebraska, Kansas, Indiana, and others are similar to Mehta et al. (2012) [18].

This study also reports further the DCV impacts on hydrometeorological variations from other combined DCV phases across the country. The (PDO-, TAG-, WPWP+) and (PDO+, TAG+, WPWP+) phase combinations increase rainfall in a wide area of the corn belt states as similar for the impacts of (PDO+, TAG-, WPWP-). However, some DCV phase combinations also severely decrease rainfall in the Southeast region except Florida in some cases. Given the same DCV phase combination, the results of DCV impacts on precipitation and drought are trivially consistent in most areas.

Essentially, the DCV phase combinations exert regionally differentiated influences on growing degree day, precipitation, and drought in many major crop growing areas such as in the Missouri River Basin and other regions which produce corn, soybeans, and wheat extensively for the United States.

\section{Conclusions}

An improved understanding of DCV on weather is very important because farmers and policy makers need to know the likely climate trajectory for the coming decades and its impacts for applications to agricultural production and other economic activities.

This study has the same findings for the contiguous states from the Missouri River Basin as in Mehta et al. (2012) [18], that: (1) during the positive PDO phase, precipitation was above average almost everywhere and temperatures were generally lower than average; (2) in positive TAG phases, precipitation was found to be below average almost everywhere and temperatures increased almost everywhere; and (3) WPWP impacts varied by subarea and had less influence than PDO and TAG in the Basin.

This study extends the results from Mehta et al. (2012) [18] by reporting that DCV phenomena have regional effects on growing degree day, precipitation, and drought across the United States. In particular, effects are found in the major production areas of corn, soybeans, and wheat, such as the Corn Belt and most of the Southeastern United States. Thus, the empirical results suggest that DCV phenomena could influence hydroclimatic variations, which in turn possibly affect crop production among other sectors regionally across the United States.

There are some limitations in this study. The author used a limited set of years and better estimates might arise under a longer period of study. Future research can cover the increasing effects of anthropogenically forced climate change, variation in solar radiation, and dynamics of jet streams in the climate regressions. Future studies also can cover analyses of DCV impacts on higher moments of the distributions to understand the impacts on variations and skewness of growing degree day, precipitation, and drought. For example, higher variance implies more uncertainty. In terms of skewness, a positive effect in regression coefficient means there is a longer right tail and more concentrated mass of distribution on the left side of the distribution. Thus, there are relatively lower (below the mean) outcomes, e.g., lower level of rainfall or lower PDSI, which means more severe drought.

Despite the limitations, this study adds value to the literature by presenting findings which provide information of DCV impacts on weather in crop-growing seasons that allows adjustments in planning and policy for the United States.

Supplementary Materials: The following are available online at http:/ / www.mdpi.com/2225-1154/6/2/43/s1, Table S1: Regression Results. 
Author Contributions: The author conducted all works.

Acknowledgments: The author would like to express his sincere gratitude and appreciation for all continuous supports and mentorship from Professors Bruce A. McCarl and Ximing Wu at Texas A\&M University. Suggestions and comments from two anonymous reviewers are gratefully acknowledged. The author thankfully appreciate Kayla Soo Young Song and Meng Wu for their proofreading.

Conflicts of Interest: The author declares no conflict of interest.

\section{Appendix A}

PDO

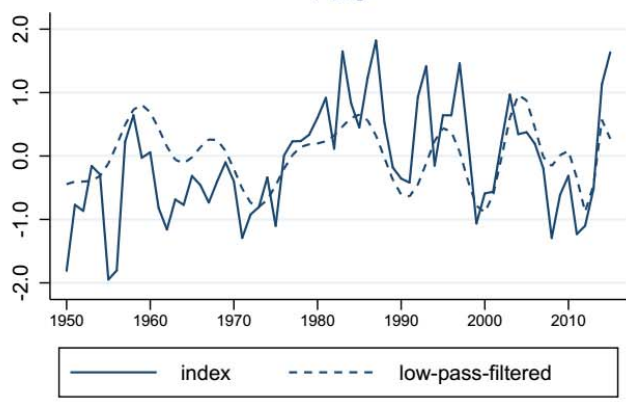

WPWP

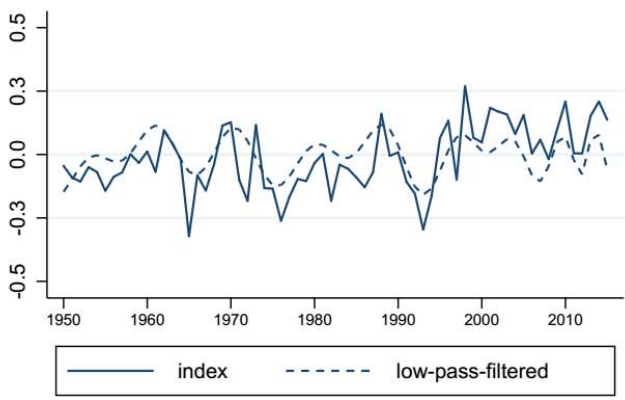

TAG

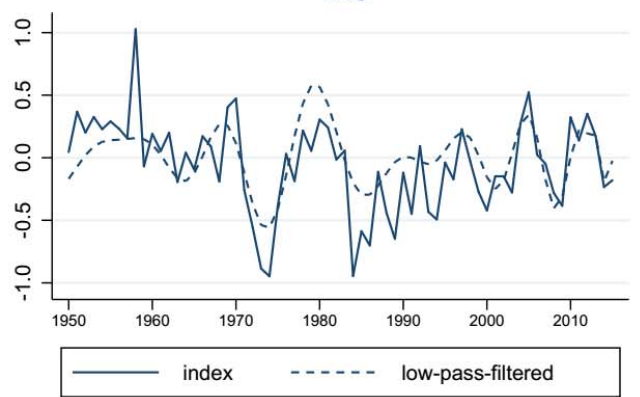

DCV phase combinations

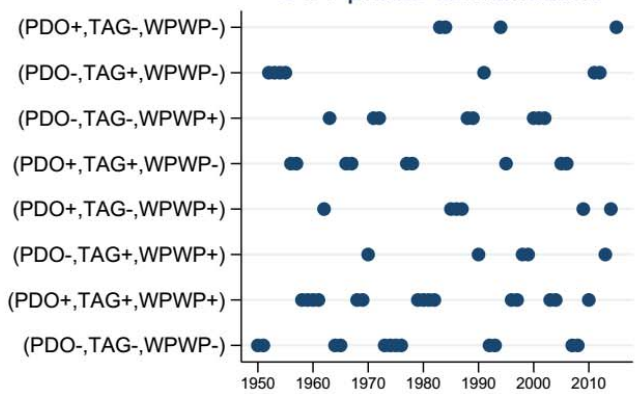

Figure A1. Annual average of three DCV indices from 1950 to 2015 and their low-pass-filtered time-series, and the corresponding frequencies of DCV phase combinations based on the filtered DCV indices. The mean value has been removed from each series. The WPWP is also detrended by regressing with the time trend and subtracting with its fitted trend. This study applies a Butterworth filter with a cutoff period of eight years.

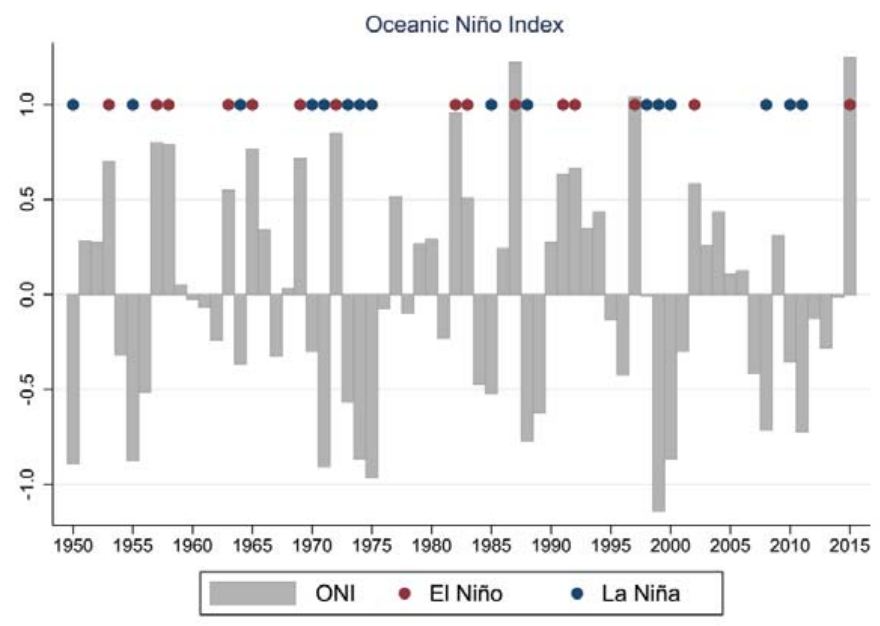

Figure A2. Oceanic Niño Index (ONI) and El Niño/ La Niña events. 


\section{References}

1. Mehta, V.M. Variability of the Tropical Ocean Surface Temperatures at Decadal-Multidecadal Timescales. Part I: The Atlantic Ocean. J. Clim. 1998, 11, 2351-2375. [CrossRef]

2. Wang, H.; Mehta, V.M. Decadal Variability of the Indo-Pacific Warm Pool and Its Association with Atmospheric and Oceanic Variability in the NCEP-NCAR and SODA Reanalyses. J. Clim. 2008, 21, 5545-5565. [CrossRef]

3. Murphy, J.; Kattsov, V.; Keenlyside, N.; Kimoto, M.; Meehl, G.; Mehta, V.; Pohlmann, H.; Scaife, A.; Smith, D. Towards Prediction of Decadal Climate Variability and Change. Procedia Environ. Sci. 2010, 1, 287-304. [CrossRef]

4. Mehta, V.M.; Wang, H.; Mendoza, K. Decadal Predictability of Tropical Basin Average and Global Average Sea Surface Temperatures in CMIP5 Experiments with the HadCM3, GFDL-CM2. 1, NCAR-CCSM4, and MIROC5 Global Earth System Models. Geophys. Res. Lett. 2013, 40, 2807-2812. [CrossRef]

5. Mehta, V.M. Natural Decadal Climate Variability: Societal Impacts; CRC Press: Boca Raton, FL, USA, 2017.

6. Mantua, N.J.; Hare, S.R.; Zhang, Y.; Wallace, J.M.; Francis, R.C. A Pacific Interdecadal Climate Oscillation with Impacts on Salmon Production. Bull. Am. Meteorol. Soc. 1997, 78, 1069-1079. [CrossRef]

7. Ting, M.; Wang, H. Summertime US Precipitation Variability and Its Relation to Pacific Sea Surface Temperature. J. Clim. 1997, 10, 1853-1873. [CrossRef]

8. Mantua, N.J. The Pacific Decadal Oscillation and Climate Forecasting for North America. Clim. Risk Solut. $1999,1,10-13$.

9. Smith, S.R.; Legler, D.M.; Remigio, M.J.; O'Brien, J.J. Comparison of 1997-98 US Temperature and Precipitation Anomalies to Historical ENSO Warm Phases. J. Clim. 1999, 12, 3507-3515. [CrossRef]

10. Mantua, N.J.; Hare, S.R. The Pacific Decadal Oscillation. J. Oceanogr. 2002, 58, 35-44. [CrossRef]

11. Wang, C.; Enfield, D.B. The Tropical Western Hemisphere Warm Pool. Geophys. Res. Lett. 2001, 28, $1635-1638$. [CrossRef]

12. Wang, C.; Enfield, D.B.; Lee, S.; Landsea, C.W. Influences of the Atlantic Warm Pool on Western Hemisphere Summer Rainfall and Atlantic Hurricanes. J. Clim. 2006, 19, 3011-3028. [CrossRef]

13. Zhang, Y.; Wallace, J.M.; Battisti, D.S. ENSO-like Interdecadal Variability: 1900-93. J. Clim. 1997, 10, 1004-1020. [CrossRef]

14. Latif, M.; Barnett, T.P. Causes of Decadal Climate Variability over the North Pacific and North America. Science 1994, 266, 634-637. [CrossRef] [PubMed]

15. Schwierz, C.; Appenzeller, C.; Davies, H.C.; Liniger, M.A.; Müller, W.; Stocker, T.F.; Yoshimori, M. Challenges Posed by and Approaches to the Study of Seasonal-to-Decadal Climate Variability. Clim. Chang. 2006, 79, 31-63. [CrossRef]

16. Meehl, G.A.; Hu, A.; Tebaldi, C. Decadal Prediction in the Pacific Region. J. Clim. 2010, 23, $2959-2973$. [CrossRef]

17. Mehta, V.M.; Rosenberg, N.J.; Mendoza, K. Simulated Impacts of Three Decadal Climate Variability Phenomena on Water Yields in the Missouri River Basin. J. Am. Water Resour. Assoc. 2011, 47, 126-135. [CrossRef]

18. Mehta, V.M.; Rosenberg, N.J.; Mendoza, K. Simulated Impacts of Three Decadal Climate Variability Phenomena on Dryland Corn and Wheat Yields in the Missouri River Basin. Agric. For. Meteorol. 2012, 152, 109-124. [CrossRef]

19. Wang, H.; Ting, M. Covariabilities of Winter US Precipitation and Pacific Sea Surface Temperatures. J. Clim. 2000, 13, 3711-3719. [CrossRef]

20. Wang, H.; Fu, R.; Kumar, A.; Li, W. Intensification of Summer Rainfall Variability in the Southeastern United States during Recent Decades. J. Hydrometeorol. 2010, 11, 1007-1018. [CrossRef]

21. Méndez, M.; Magaña, V. Regional Aspects of Prolonged Meteorological Droughts over Mexico and Central America. J. Clim. 2010, 23, 1175-1188. [CrossRef]

22. Mehta, V.M.; Knutson, C.L.; Rosenberg, N.J.; Olsen, J.R.; Wall, N.A.; Bernadt, T.K.; Hayes, M.J. Decadal Climate Information Needs of Stakeholders for Decision Support in Water and Agriculture Production Sectors: A Case Study in the Missouri River Basin. Weather Clim. Soc. 2013, 5, 27-42. [CrossRef]

23. NOAA National Climatic Data Center. Monthly Summaries Global Historical Climatology Network (GHCND). Available online: http://www.ncdc.noaa.gov/cdo-web/\#t=secondTabLink (accessed on 16 March 2017). 
24. NOAA National Climatic Data Center's Climate Data Online. (NCDC CDO). Available online: https: / / www7.ncdc.noaa.gov/CDO/CDODivisionalSelect.jsp (accessed on 16 March 2017).

25. University of Washington's Joint Institute for the Study of the Atmosphere and Ocean (JISAO). Available online: http:/ / research.jisao.washington.edu/pdo/PDO.latest.txt (accessed on 16 March 2017).

26. NOAA Extended Reconstructed Sea Surface Temperature (ERSST) V3b. Available online: https://www.esrl. noaa.gov/psd/data/gridded/data.noaa.ersst.v3.html (accessed on 16 March 2017).

27. Reynolds, R.W.; Rayner, N.A.; Smith, T.M.; Stokes, D.C.; Wang, W. An Improved in Situ and Satellite SST Analysis for Climate. J. Clim. 2002, 15, 1609-1625. [CrossRef]

28. NOAA Center for Weather and Climate Prediction (NCEP). Changes to the Oceanic Niño Index (ONI). Available online: http://www.cpc.ncep.noaa.gov/products/analysis_monitoring/ensostuff/ensoyears. shtml (accessed on 16 March 2017).

29. Henze, N. A Probabilistic Representation of the Skew-Normal Distribution. Scand. J. Stat. 1986, 13, $271-275$.

30. Azzalini, A.; Valle, A.D. The Multivariate Skew-Normal Distribution. Biometrika 1996, 83, 715-726. [CrossRef]

31. Azzalini, A.; Capitanio, A. Statistical Applications of the Multivariate Skew Normal Distribution. J. R. Stat. Soc. 1999, 61, 579-602. [CrossRef]

32. Gupta, A.K.; Chen, T. Goodness-of-Fit Tests for the Skew-Normal Distribution. Commun. Stat.-Simul. Comput. 2001, 30, 907-930.

33. Azzalini, A. A Class of Distributions which includes the Normal Ones. Scand. J. Stat. 1985, 12, 171-178.

34. Bretherton, C.S.; Widmann, M.; Dymnikov, V.P.; Wallace, J.M.; Bladé, I. The Effective Number of Spatial Degrees of Freedom of a Time-varying Field. J. Clim. 1999, 12, 1990-2009. [CrossRef]

35. McKinley, G.A.; Takahashi, T.; Buitenhuis, E.; Chai, F.; Christian, J.R.; Doney, S.C.; Jiang, M.S.; Lindsay, K.; Moore, J.K.; Le Quere, C.; et al. North Pacific Carbon Cycle Response to Climate Variability on Seasonal to Decadal Timescales. J. Geophys. Res. Oceans 2006. [CrossRef]

36. Wyatt, M.G.; Kravtsov, S.; Tsonis, A.A. Atlantic Multidecadal Oscillation and Northern Hemisphere's Climate Variability. Clim. Dyn. 2012, 38, 929-949. [CrossRef]

37. McCarthy, G.D.; Haigh, I.D.; Hirschi, J.J.M.; Grist, J.P.; Smeed, D.A. Ocean Impact on Decadal Atlantic Climate Variability Revealed by Sea-level Observations. Nature 2015, 521, 508-510. [CrossRef] [PubMed]

(C) 2018 by the author. Licensee MDPI, Basel, Switzerland. This article is an open access article distributed under the terms and conditions of the Creative Commons Attribution (CC BY) license (http:/ / creativecommons.org/licenses/by/4.0/). 